\title{
Life-Cycle Management Strategy on Steel Girders in Bridges
}

\author{
Kevin K. L. So, ${ }^{1}$ Moe M. S. Cheung, ${ }^{2}$ and Eric X. Q. Zhang ${ }^{3}$ \\ ${ }^{1}$ Faculty of Science and Technology, The Technological and Higher Education Institute of Hong Kong, Tsing Yi Island, Hong Kong \\ ${ }^{2}$ Department of Building Engineering, Tongji University, China \\ ${ }^{3}$ Department of Civil and Environmental Engineering, The Hong Kong University of Science and Technology, \\ Clear Water Bay, Hong Kong
}

Correspondence should be addressed to Kevin K. L. So, kevin@ust.hk

Received 16 December 2011; Revised 22 May 2012; Accepted 23 May 2012

Academic Editor: Sami W. Tabsh

Copyright (c) 2012 Kevin K. L. So et al. This is an open access article distributed under the Creative Commons Attribution License, which permits unrestricted use, distribution, and reproduction in any medium, provided the original work is properly cited.

\begin{abstract}
The major problems affecting the service life of bridges are related to various factors such as fatigue-sensitive details, increased service loads, corrosion deterioration, and the lack of proper maintenance. Among them, corrosion deterioration and fatigue damages of structures particularly to steel girder bridges are the most common ones. Bridges of different structural forms, at different locations or under different climates, may suffer from various degrees of deterioration. Steel girders at different positions of a bridge may also suffer from different degrees of damage. How to effectively maintain the bridge asset at a minimal cost and how to predict the time for future works are crucial, particularly when government funding sources become stretched. A comprehensive bridge management framework assisting stakeholders to appropriately and reasonably prioritize their future maintenance-related works in their bridge stocks, such that stakeholders can better allocate the limited resources, is utmost concerned. This paper proposes an integrated life-cycle management (LCM) strategy on steel girders in bridges in which corrosion deterioration and fatigue damage prediction models are mapped with girders' performance conditions. A practical example to demonstrate the applicability of the proposed LCM strategy is also illustrated.
\end{abstract}

\section{Introduction}

In recent decades, the long life of active use of transport infrastructure has become a worldwide issue. The developmental spending or investment for preparation of new infrastructures is becoming very difficult in all over the world particularly due to the poor economic condition. The life extension of the bridges not just makes the large economic profit, but also alleviates the financial burden on asset management, and effective decreases in the global warming and other environmental pollutions in life cycle of structure. Bridges are essential in transport infrastructure, and bridge maintenance or replacement is one of the largest expenditure items in the bridge life span.

In Japan, much infrastructure was constructed to support the spreading transportation network from 1950's to the 1970's. Recently, many infrastructures in Japan are getting old, and the numbers of bridges that have been in active service more than 50 years are increasing dramatically, and it is expected that these bridges will be more than 50,000 in 2021. From reasons, the inspection, maintenance, and rehabilitation planning are very important problem for longlived active use of bridge and infrastructure [1]. In Australia, there are over 30,000 roads and rail bridges. For example, the Queensland government allocated \$350 million towards replacing approximately 100 old and obsolete road bridges in regional Queensland over the next five years, from 2006 to 2010 [2]. In USA, more than $43 \%$ of the bridges are made of steel. Currently, there are 190,000 steel bridges (simply supported and continuous) of which over 40,000 $(25 \%)$ are structurally deficient and over 35,000 (18.5\%) are functionally obsolete [3].

\section{Steel Bridge Problems}

The major problems affecting the service life of bridges are related to various factors such as fatigue-sensitive details, increased service loads, corrosion deterioration, and the lack of proper maintenance [4]. Among typical types of damage as shown in Figure 1, corrosion deterioration and fatigue 


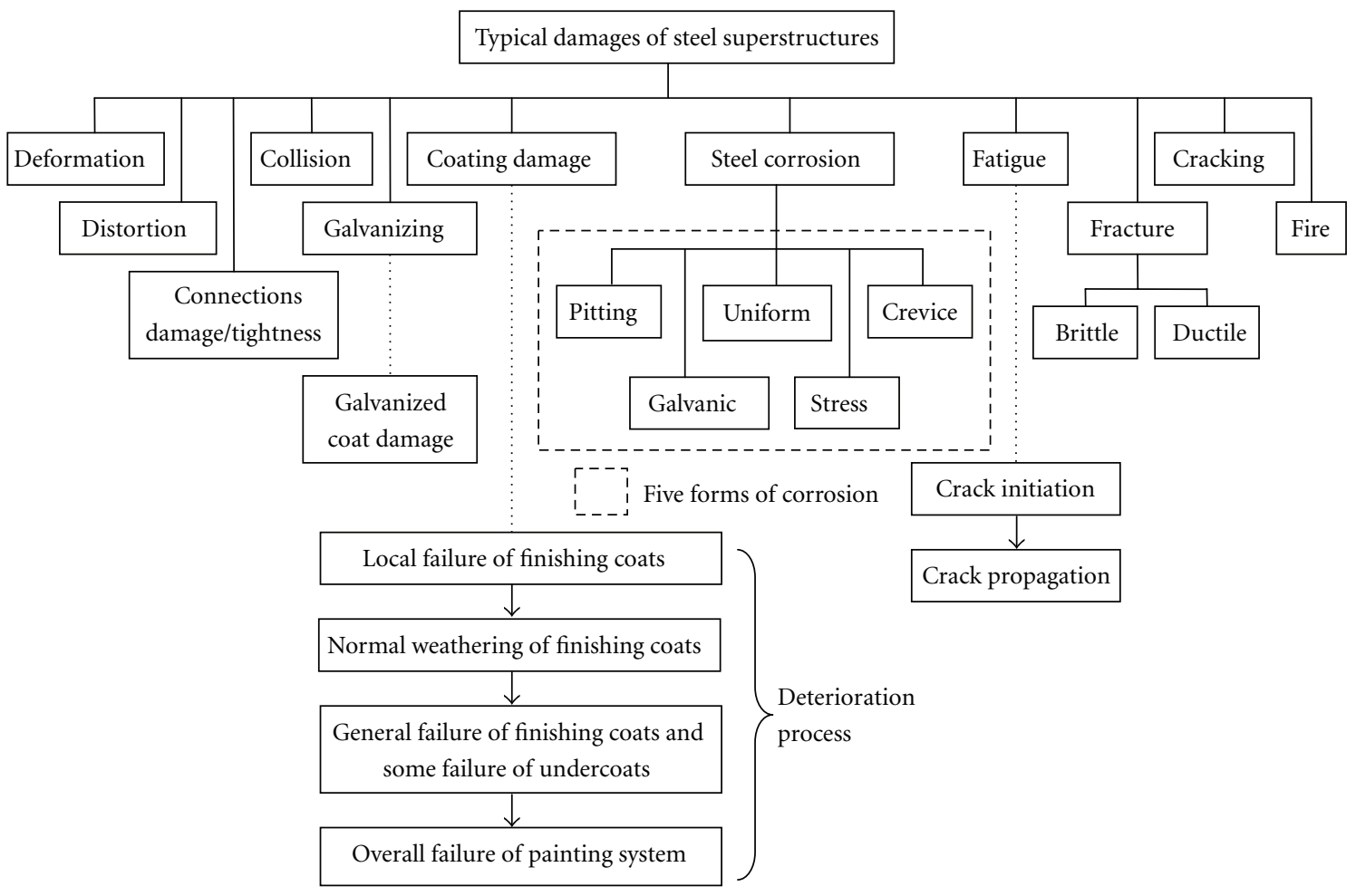

FIgURE 1: Typical types of damage of steel superstructures.

damages of structures particularly to steel girder bridges are the most common ones which are influenced by the environment and the vehicle loadings and its stress ranges.

In conventional practice, inspection, maintenance, or repair works are scheduled in accordance with the maintenance and rehabilitation manual and the maintenance authority would conduct scheduled works and record all the findings accordingly. However, the manual basically is a typical one rather than being specially made for a particular asset. Bridges of different structural forms, at different locations or under different climates, may suffer from various degrees of deterioration. Steel girders at different positions of a bridge may also suffer from different degrees of damage. How to effectively maintain the bridge asset at a minimal cost and how to predict the time for future works are important issues, when government funding sources become stretched.

To relieve the long-term financial burden on asset maintenance, whole life-cycle management (LCM) concept has been introduced in recent decade and is now getting more important in engineering design, construction, and management. In the whole LCM concept, the prediction of structural member deterioration is essential to plan for future maintenance actions. This paper proposes an integrated LCM strategy on steel girders in bridges in which corrosion deterioration and fatigue damage prediction models are mapped with girders' performance conditions. A practical example to demonstrate the applicability of the proposed strategy is also illustrated.

\section{LCM in Steel Girder Bridge}

This paper proposes an integrated LCM strategy considering three structural assessment factors altogether simultaneously: (1) the serviceability limit: deflection; (2) the ultimate limits: moment and shear, and (3) the fatigue strength limit. Clearly, the ultimate limits are not only two considerations, moment and shear. The bearing capacity can also be affected by corrosion. However, in common practice, if a steel bridge will not receive proper maintenance and painting, it will probably be constructed with bearing stiffeners to increase the bearing capacity. In order to reduce the complexity in showing the implementation of proposed integrated LCM strategy, the technical analysis of bearing behavior is not included in the paper. A steel girder bridge is provided as an example to demonstrate the use of the proposed strategy with corrosion deterioration and fatigue damage models being incorporated.

\section{Corrosion Deterioration Model}

Except for high-performance steel such as anticorrosion weathering steel, steel girder bridges are usually subject to corrosion to certain degrees. If undetected over a period of time, corrosion will weaken webs and flanges of steel girders by reducing the material thickness and possibly lead to dangerous structural failures [7].

In serviceability limit analysis, measurements of remaining thickness of corroded steel web and bottom flange are 
TAble 1: Statistical parameters for $A$ and $B[5,6]$.

\begin{tabular}{|c|c|c|c|c|}
\hline \multirow{2}{*}{ Parameters } & \multicolumn{2}{|c|}{ Carbon steel } & \multicolumn{2}{|c|}{ Weathering steel } \\
\hline & $A(\mu \mathrm{m})$ & $B$ & $A(\mu \mathrm{m})$ & $B$ \\
\hline \multicolumn{5}{|l|}{ (a) Rural environment } \\
\hline Mean value, $\mu$ & 34.0 & 0.65 & 33.3 & 0.498 \\
\hline Coefficient of variation, $\sigma / \mu$ & 0.09 & 0.10 & 0.34 & 0.09 \\
\hline Coefficient of correlation, $\rho_{A B}$ & - & - & -0.05 & - \\
\hline \multicolumn{5}{|l|}{ (b) Urban Environment } \\
\hline Mean value, $\mu$ & 80.2 & 0.593 & 50.7 & 0.567 \\
\hline Coefficient of variation, $\sigma / \mu$ & 0.42 & 0.4 & 0.30 & 0.37 \\
\hline Coefficient of correlation, $\rho_{A B}$ & 0.68 & - & 0.19 & - \\
\hline \multicolumn{5}{|l|}{ (c) Marine Environment } \\
\hline Mean value, $\mu$ & 70.6 & 0.789 & 40.2 & 0.557 \\
\hline Coefficient of variation, $\sigma / \mu$ & 0.66 & 0.49 & 0.22 & 0.10 \\
\hline Coefficient of correlation, $\rho_{A B}$ & -0.31 & - & -0.45 & - \\
\hline
\end{tabular}

commonly considered. The effective thicknesses of webs and flanges are reduced with time as [7]:

$$
\begin{gathered}
t_{f}(t)=t_{f 0}-C(t), \\
t_{w}(t)=t_{w 0}-2 C(t),
\end{gathered}
$$

where $t_{f 0}=$ the initial flange thickness $(\mathrm{mm}), t_{w 0}=$ the initial web thickness $(\mathrm{mm}), C(t)=$ the average corrosion penetration $(\mathrm{mm})$ at time $t$.

Corrosion is influenced by the environment such as the amount of moisture in the air and the presence of salt. There is a common agreement that the corrosion time versus penetration rate can be modeled, with a good approximation, by an exponential function [8]:

$$
C(t)=A t^{B},
$$

where $C(t)=$ average corrosion penetration in micrometres $(\mu \mathrm{m})$ after $t$ years, $t=$ time (years) of exposure, $A=$ corrosion loss parameter after one year of exposure, and $B=$ parameter determined from regression analysis of experimental data.

Parameters $A$ and $B$ were determined by Albrecht and Naeemi [5] and further verified by Kayser [6] as shown in Table 1.

Researchers have pursued extensive studies to predict time-variant corrosion propagation to capture the actual corrosion. However, these studies often neglect the influence of the periodic repainting effect on the corrosion process $[3,6,8-10]$.

Lee et al. [7], based on previous studies, introduced a modified corrosion propagation model with periodic repainting as shown in (3). Lee's corrosion model is adopted for service life prediction of steel girders in this paper.

$$
p_{i}(t)= \begin{cases}C\left(t-i T_{\mathrm{REP}}-T_{\mathrm{CI}}\right)^{m} & \text { for }(i) T_{\mathrm{REP}}+\mathrm{T}_{\mathrm{CI}} \\ p_{i-1}\left(i T_{\mathrm{REP}}\right), & \text { otherwise, }\end{cases}
$$

where $p_{i}(t)$ is corrosion propagation depth in micrometer $(\mu \mathrm{m})$ at time $t$ in years during $i$ th repainting period; $C$ is random corrosion rate parameter; $m$ is random time-order parameter; and $T_{\mathrm{CI}}, T_{\mathrm{REP}}=$ random corrosion initiation and periodic repainting period (yrs), respectively.

\section{Fatigue Damage Model}

Several models have been developed to describe the process of fatigue damage, including the $\mathrm{S}-\mathrm{N}$ model, the Miner's linear cumulative fatigue damage model, and the crack growth model under linear-elastic fracture mechanics (LEFM) approach [8]. S-N and Miner's models both have limitation in addressing the probabilistic nature, whereas LEFM approach based on crack propagation theory yields more accurate results for fatigue and fracture reliability assessment if the current crack size is measured [5]. Since the effect of crack size is taken into consideration, this approach yields more accurate results for fatigue and fracture reliability assessment if the current crack size can be measured [6]. In welded bridge details, the welding process inherently results in initial flaws from which crack growth may occur under cyclic loadings [9].

The commonly used crack growth model is the ParisErdogan model which is simplified to determine the required cycles for fatigue failure and this model is adopted for service life prediction in this paper. The number of cycle required to grow for fatigue crack can be estimated by taking integration from initial crack dimension $a_{0}$ to critical crack dimension $a_{c}$ [11]. Zhao's model equation is shown in (4):

$$
\int_{a_{0}}^{a_{c}} \frac{d a}{[F(a) \sqrt{\pi a}]^{m}}=\int_{N_{0}}^{N_{c}} C S^{m} d N
$$

where $F(a)=F_{e} F_{s} F_{w} F_{g}$ is defined as the crack-sizedependent correction factor; $F_{e}$ is crack the shape correction factor; $F_{s}$ is the front free surface correction factor; $F_{w}$ is the finite plate width correction factor; $F_{g}$ is the stress gradient 


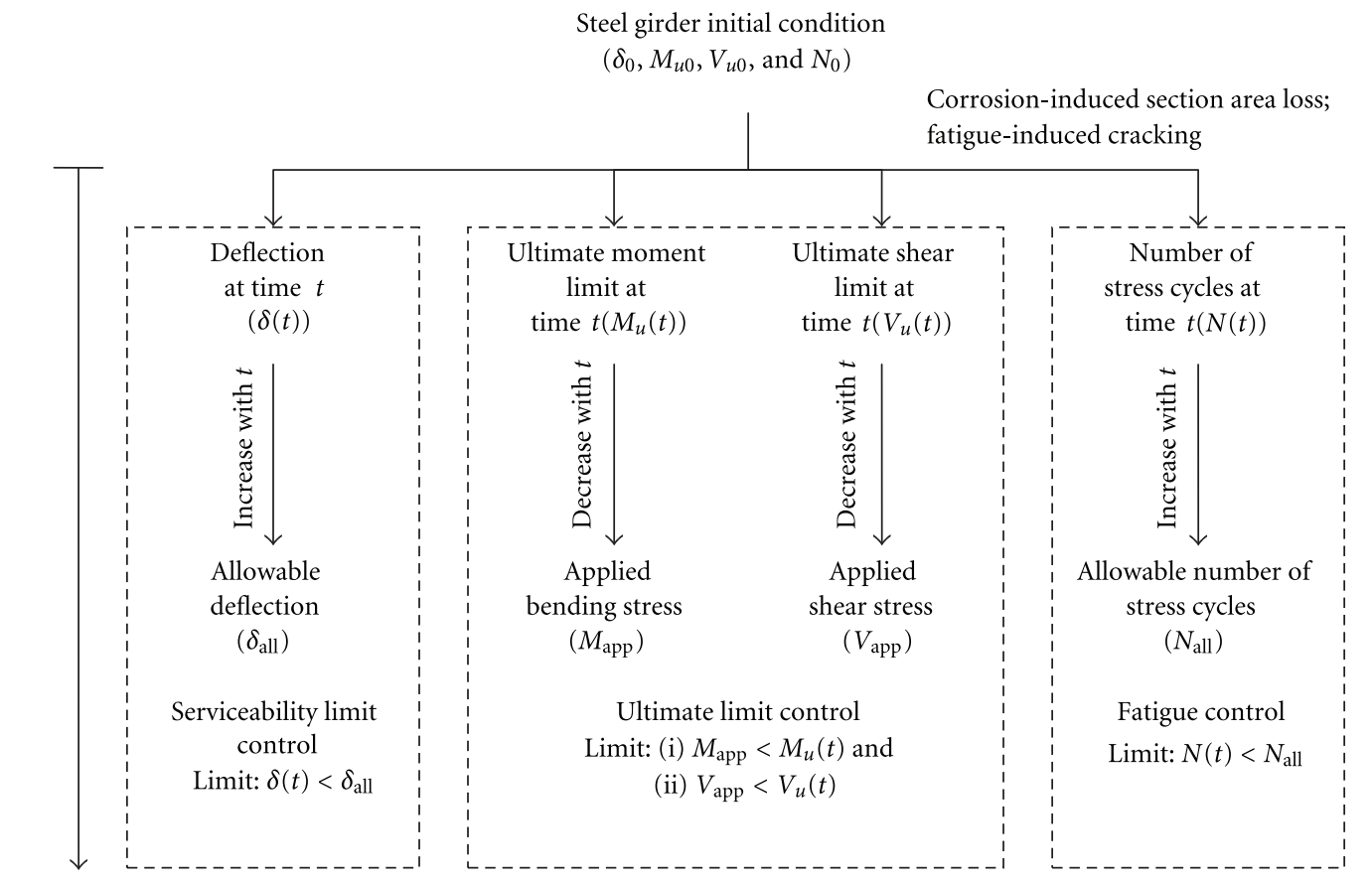

Time $t(\mathrm{yr})$

FIGURE 2: Integrated LCM strategy on steel bridge girders due to corrosion and fatigue.

correction factor; $S$ is the stress range; $C$ is the crack growth constant:

$$
\begin{aligned}
\int_{N_{0}}^{N_{c}} C S^{m} d N & =C \sum_{i=1}^{k} S_{i}^{m}\left(N_{i c}-N_{i 0}\right) \\
\int_{N_{0}}^{N_{c}} C S^{m} d N & =C \sum_{i=1}^{k} S_{i}^{m}\left(N_{i c}-N_{i 0}\right) \\
& =C S_{r \text { Miner }}^{m} N_{T} .
\end{aligned}
$$

Since randomly variable loading was involved in every case of fatigue crack propagation, an effective stress intensity range was used based on Miner's rule and the corresponding Miner's effective stress. $S_{r \text { Miner }}$ is the effective stress range while the $N_{T}$ is the required number of cycles to cause fatigue failure. The crack growth component $m$ equal to 3 has been observed to be applicable to basic crack growth rate data for structural steels as well as test data on welded members. The corresponding mean value of growth constant $C$ was found to be $1.26 \times 10^{-13}[11,12]$. Equation (4) can be further simplified to determine the required cycles for fatigue failure:

$$
N_{T}=\int_{a_{0}}^{a_{c}} \frac{d a}{1.26 \times 10^{-13}\left[F(a) S_{r \text { Miner }} \sqrt{\pi a}\right]^{3}} .
$$

Having estimated the fatigue life in cycles, $N_{T}$, for the steel component, the data on average daily traffic specific to the bridge roadway, distribution of traffic volume per traffic lane, and expected traffic growth in future years are used to convert $N_{T}$ in terms of time measures in years. If $t=$ fatigue life in years, then

$$
N_{T}=(1+r)^{t} \operatorname{ADTT}(365) S_{c},
$$

where $r$ is the yearly rate of traffic volume increase, ADTT is a random variable representing the average daily truck traffic and $S_{c}$ is a random variable representing equivalent number of stress range cycles per truck crossing. The remaining fatigue life will be $t-t_{0}$, where $t_{0}$ is the current age of the steel component in years [13].

\section{Integrated Life-Cycle Management Strategy}

Corrosion deterioration and fatigue damages may weaken structural members and result in the increment of deflection, the reduction of ultimate bending, and shear strengths and the reduction of fatigue strength. The above corrosion and fatigue models with integration of predefined limits as below form service life prediction models to predict the service condition of steel members at any time throughout its life.

Conventional LCM is based on fixed predefined limit states either the serviceability limit (i.e., deflection) or the ultimate limits (i.e., moment and shear capacities) or the fatigue strength limit. However, it may not be always true that the one limit dominates over one another or vice versa in all circumstances. This paper proposes collective considerations of the serviceability limit:deflection, the ultimate limits:moment and shear, and the fatigue strength limit simultaneously which are essential in the further life-cycle cost (LCC) analysis. This proposed LCM strategy on steel girders covering serviceability limit, ultimate limits, and fatigue strength limit is graphically illustrated in Figure 2. 


\section{Definition of Limits}

All structures have two basic requirements in common: safety from collapse and satisfactory performance of the structure for its intended use. The limit states usually define the various ways in which a structure fails to satisfy these basic requirements.

7.1. Serviceability Limit. Serviceability limit states usually relate to satisfactory performance and correspond to excessive deflection, vibration and local deformation. In this paper, the serviceability limit is defined in terms of deflection of a girder at any time, $\delta(t)$, in the design life. If the deflection exceeds the code requirement, $\delta_{\text {all }}$, a serviceability failure is assumed to occur. It is also assumed that replacement or rehabilitation works must be conducted before girders reaching its deflection limit.

7.2. Ultimate Limits. Ultimate limit states usually relate to safety and correspond to strength, stability, and very large deformation. In the paper, the ultimate limits are governed by the structural capacity condition in bending, $M$, and shear, $V$, for any time in the life span. It is assumed that replacement or rehabilitation works must be conducted before the ultimate moment or shear capacity of the girder, $M_{u}(t)$ and $V_{u}(t)$, reaches the total applied moment or shear.

7.3. Fatigue Strength Limit. The fatigue strength limit suggested in this paper is defined in terms of accumulated numbers of stress cycles at any time, $N(t)$, throughout its life. If the number of stress cycles exceeds to its allowable, $N_{\text {all }}$, a fatigue failure is assumed to occur. Similarly, it is assumed that replacement or rehabilitation works must be conducted before reaching the limit.

7.4. Performance-Based Models. To mathematically present the condition of structural members towards its limits at particular time, buffer functions, $F(t)$, measured in percentagefor each limit are then formulated accordingly as (8) to (11) where subscripts $\delta, M, V$, and $N$ for $F(t)$ refer to buffer functions for deflection, moment, shear and fatigue strength, respectively, and subscripts DL, SDL, LL, and I for $M$ or $V$ refer to moment or shear induced by dead load, superimposed dead load, live load, and impact load respectively:

$$
\begin{gathered}
F_{\delta}(t)=\frac{\delta_{\text {all }}-\delta(t)}{\delta_{\text {all }}}, \\
F_{M}(t)=\frac{M_{\mathrm{u}}(t)-M_{\mathrm{DL}}-M_{\mathrm{SDL}}-M_{\mathrm{LL}}-M_{\mathrm{I}}}{M_{\mathrm{u}}(t)}, \\
F_{V}(t)=\frac{V_{\mathrm{u}}(t)-V_{\mathrm{DL}}-V_{\mathrm{SDL}}-V_{\mathrm{LL}}-V_{\mathrm{I}}}{V_{\mathrm{u}}(t)}, \\
F_{N}(t)=\frac{N_{\text {all }}-N(t)}{N_{\mathrm{all}}} .
\end{gathered}
$$

\section{Assignment of Condition States to the Steel Girder}

In the proposed LCM strategy, four performance condition states, Good $(G)$, Satisfactory $(S)$, Fair $(F)$, and Poor $(P)$ are assigned to the percentage range of the deflection, the moment, the shear, and the fatigue strength buffer as mentioned above, respectively. Minimum acceptable criteria for Good $\left(G_{\min }\right)$, Satisfactory $\left(S_{\min }\right)$, and Fair $\left(F_{\min }\right)$ conditions are also needed to be defined.

$$
\Omega_{j}= \begin{cases}G & F_{\delta}(t) \geq G_{\min }, \\ S & S_{\min } \leq F_{\delta}(t)<G_{\min }, \\ F & F_{\min } \leq F_{\delta}(t)<S_{\min } \\ P & F_{\delta}(t)<F_{\min } .\end{cases}
$$

Let $\Omega_{j}$ denote the set of possible limit states, then, $j=$ $1,2,3$, and 4 with respect to different limits: deflection, bending moment, shear, and fatigue accordingly. The general performance condition model as (12) is further modified as follows.

Serviceability Limit. For deflection:

$$
\Omega_{1}= \begin{cases}G & F_{\delta}(t) \geq 15 \% \\ S & 10 \% \leq F_{\delta}(t)<15 \% ; \\ F & 5 \% \leq F_{\delta}(t)<10 \% ; \\ P & F_{\delta}(t)<5 \% .\end{cases}
$$

Ultimate Limits. For bending moment:

$$
\Omega_{2}= \begin{cases}G & F_{M}(t) \geq 40 \% \\ S & 30 \% \leq F_{M}(t)<40 \%, \\ F & 20 \% \leq F_{M}(t)<30 \%, \\ P & F_{M}(t)<20 \%\end{cases}
$$

for shear:

$$
\Omega_{3}= \begin{cases}G & F_{V}(t) \geq 40 \% \\ S & 30 \% \leq F_{V}(t)<40 \% \\ F & 20 \% \leq F_{V}(t)<30 \%, \\ P & F_{V}(t)<20 \%\end{cases}
$$

Fatigue Strength Limit. For fatigue strength:

$$
\Omega_{4}= \begin{cases}G & F_{N}(t) \geq 40 \%, \\ S & 30 \% \leq F_{N}(t)<40 \%, \\ F & 20 \% \leq F_{N}(t)<30 \%, \\ P & F_{N}(t)<20 \% .\end{cases}
$$

The percentage ranges of buffers for different limit states are in fact various dependent on the stakeholders' decisions. Several factors, such as long-term costs, project risks, environmental policies, or local maintenance practices, may affect the decision of stakeholders. In this paper, for demonstration purpose, the percentage ranges of buffers are 
assumed as shown in (13) to (16) and " $F$ " condition state is also assumed as the minimum acceptable condition level. Once acceptable service condition states for each limit have been predefined, future replacement or rehabilitation works shall be carried out at the time before reaching its acceptable condition limits. The predicted action time will then be adopted in the life-cycle cost model for the subsequent costbenefit analysis.

8.1. Options for LCM Strategy. In the proposed LCM strategy, the service life limits are generalized as three options.

Option 1: Serviceability Limits Control. Deflection:

$$
t_{\lim }=F_{\delta}(t)<5 \%
$$

Option 2: Ultimate Limits Control. Shear and moment capacities at time $t$ :

$$
t_{\lim }=F_{V}(t) \text { or } F_{M}(t) \leq 20 \% .
$$

Option 3: Fatigue strength Limit Control. Fatigue strength at time $t$ :

$$
t_{\lim }=F_{N}(t) \leq 20 \%
$$

\section{Methodology of the Integrated Life-Cycle Cost (LCC) Model}

LCC model is commonly used as the basis to evaluate the cost effectiveness of different management strategies. In the model, proper actions taken at appropriate time are a crucial element for the model accuracy. The LCC of a structure is a combination of the present values of all future costs of occurring within the life span of the structure. The minimum

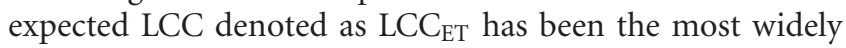
used criterion in design optimization of new structural systems considering lifetime performance. The mathematical presentation of the expected LCC of a structure over $T$ years of life span can be generalized as:

$$
\mathrm{LCC}_{\mathrm{ET}}=\sum_{i=1}^{n} \sum_{t=0}^{T}\left(\beta_{i}(t) \frac{C_{i}(t)}{(1+r)^{t}}\right),
$$

where $\mathrm{LCC}_{\mathrm{ET}}$ is expected total life-cycle cost, $C_{i}(t)$ is cost of future action $i$ at time $t, \beta_{i}$ is probability of occurrence of future action $i, r$ is a discount rate (constant discount rate assumed in the paper), $i$ is type of future actions, $t$ is time in year, and $T$ is service life span in years. The cost of future actions can be further subdivided into expected design cost $C_{\text {des }}(t)$, expected construction cost $C_{\text {con }}(t)$, expected inspection cost $C_{\text {ins }}(t)$, expected maintenance cost $C_{m}(t)$, expected replacement and rehabilitation cost $C_{\text {rep }}(t)$, expected demolition cost $C_{\mathrm{dem}}(t)$, and expected failure cost $C_{\text {fai }}(t)$, respectively. To assist better understanding of possible strategies-induced costs, the scopes of inspection, maintenance, and replacement and rehabilitation works are defined and elaborated.

\section{Inspection, Maintenance, and Replacement and Rehabilitation Strategies}

10.1. Inspection Strategy. Inspection strategies vary, depending on the policy of the stakeholders. Frequent inspections provide more updated information for future maintenance plans. However, the LCC of inspection work is usually insignificant in comparison to the whole LCC of the structure, and a cost-effective management approach should be maintained [17]. The cost of inspection work $\left(C_{\text {ins }}\right)$ is generally categorized into two kinds with defined scopes as follows.

(1) General Inspection $\left(C_{\text {ins, } 1}\right)$ A visual inspection can be conducted annually for obvious defects which might lead to safety problems or lead to loss of use of the structure or restriction of use [17]. Visual inspections allow discovering the rusting or loss of material sections. Steel members should be examined regarding (i) the condition of its protective system including protective painting or galvanizing; (ii) the condition of materials towards corrosion; (iii) the condition of connections; (iv) cracking or fracture defects; and (v) structural deformation or distortion.

(2) Detailed Inspection $\left(C_{\mathrm{ins}, 2}\right)$ Inspection work includes visual examination of all visible and accessible parts of a structure. Some minor nondestructive inspection (NDI) of representative areas would be carried out. NDI methods commonly include radiography and ultrasonics for the determination of internal defects while dye penetration and magnetic particle inspection for the detection of surface defects. The purpose of detailed inspection is to verify the deterioration state of the structure, if it is on the schedule $\mathrm{R} \& \mathrm{R}$ plan. Thus, the detailed inspection time is adjusted based on simulated $\mathrm{R} \& \mathrm{R}$ time. It is assumed that detailed inspection works shall be conducted before replacement or rehabilitation works taken place [18].

10.2. Maintenance Strategy. Maintenance of protective coatings is important for visual and physical preservation of steel components. A durable paint combination with long maintenance intervals is not only an economical but also an environmentally acceptable solution [18]. Typically, there are three types of coatings for corrosion rate reduction which are paints, steel galvanizing, and oxidized steel formed on weathering steel of a combination of these coatings. Because of the difficulty in galvanizing large sections of steel elements, the industry has generally used paints for protection. Paints or high-performance coatings, as some of the newer systems are known, are separated into three categories: the inhibitive primer, the sacrificial primer, and the barrier coat [19]. Once defects on coating surface have been found, proper cleaning on the surface and subsequent repainting works should be taken place.

10.3. Replacement and Rehabilitation (R\&R) Strategy. Repairing process of steel structural elements usually in many cases is very complex and it requires the use of advanced material solution and techniques. The most important damage to the steel bridge elements can be classified into 


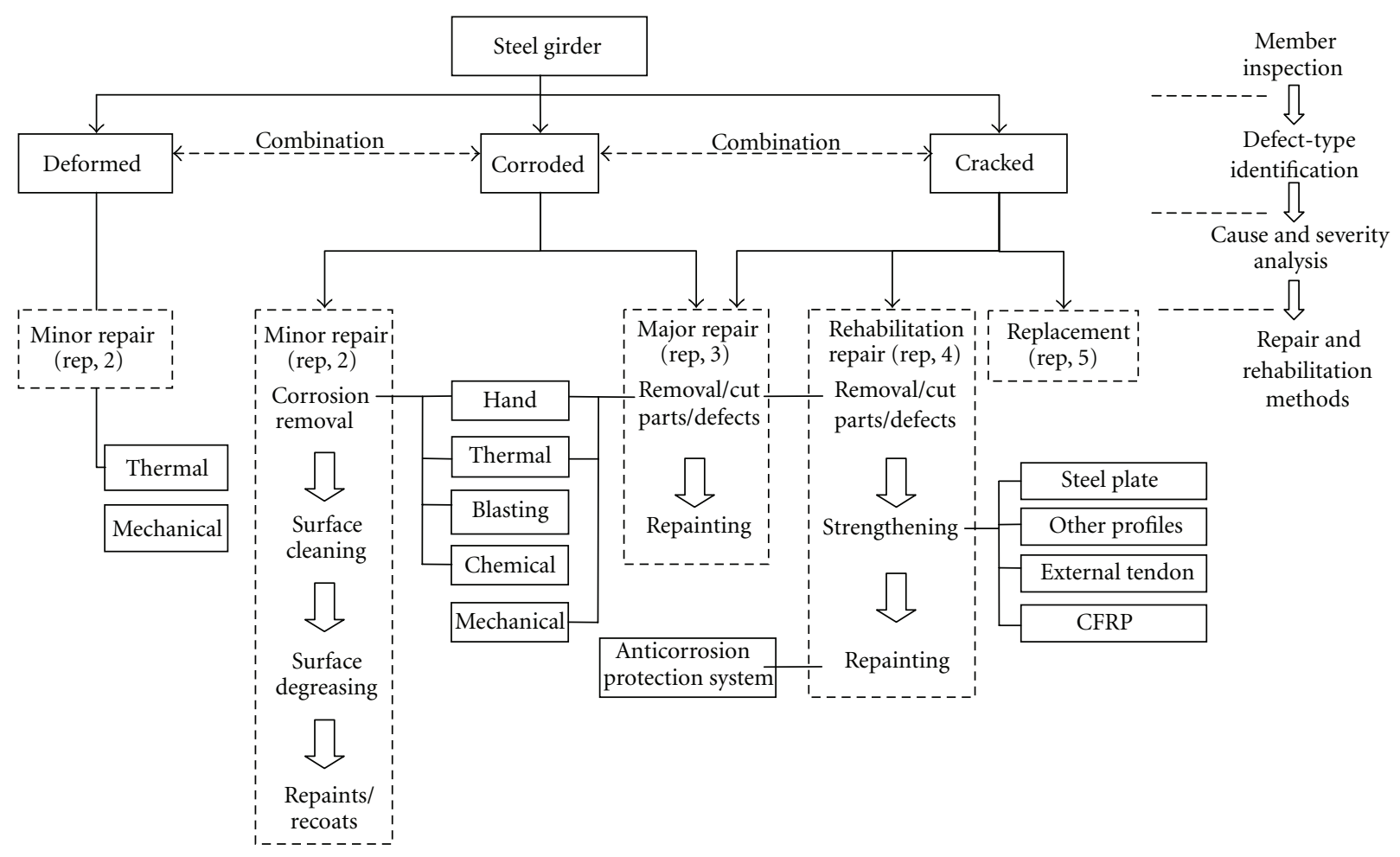

FIGURE 3: Replacement and rehabilitation methods for conventional steel girder.

TABLE 2: Proposed replacement and rehabilitation action set.

\begin{tabular}{lcl}
\hline Action description & Action matrix & Possible replacement and rehabilitation methods \\
\hline Do nothing & Rep, 1 & $\begin{array}{l}\text { Observation } \\
\text { Corrosion removal, surface cleaning, degreasing, and repainting } \\
\text { Minor repair }\end{array}$ \\
Rep, 2 & Rectify deformed parts \\
Major repair & Rep, 3 & $\begin{array}{l}\text { Removal/cut defects and parts and repainting } \\
\text { Removal/cut defects and parts, strengthening, and repainting }\end{array}$ \\
Rehabilitation repair & Rep, 4 & $\begin{array}{l}\text { Structure strengthening by steel plate } \\
\text { Structure strengthening by CFRP }\end{array}$ \\
& & Structure strengthening by external tendons \\
Replacement & Rep, 5 & Structure replaced by new members
\end{tabular}

three groups: (i) corrosion destruction of the members and/or their joints; (ii) fatigue effects in steel and its brittle fracture; (iii) mechanical fracture, including collision, of the elements themselves and/or the joints.

Before carrying out any rehabilitation works, the cause of defects and the severity of such defects towards the main structural system should be identified and subsequently analyzed. Depending on the severity and the type of damage causes, different rehabilitation techniques can be applied. General classification of the typical R\&R methods for steel girder is proposed and illustrated in Figure 3. Any R\&R work should be considered individually and it should be preceded by evaluation and assessment of the condition of the structure, the relevant theoretical analysis as well as the selection of an appropriate repair technology [20].
Regarding the degree of R\&R works, it may be classified into five different actions as shown in Table 2 and defined with specified meanings and scopes.

(1) Do nothing (Rep, 1): it means no action is carried out and there is no change in the condition of the structure.

(2) Minor repair (Rep, 2): it provides no improvement in durability performance but slows the deterioration rate such that the condition of the structure or its components could be maintained for a certain further period.

(3) Major repair (Rep, 3): it provides no improvement in durability performance but restores the durability, structural strength, and function or appearance of the 
TABLE 3: Moments and shears due to dead and superimposed dead loads ( $M_{\mathrm{DL}}, M_{\mathrm{SDL}}, V_{\mathrm{DL}}$, and $\left.V_{\mathrm{SDL}}\right)$.

\begin{tabular}{|c|c|c|c|c|c|}
\hline \multirow{2}{*}{ Girder nos. } & \multirow{2}{*}{ Position } & \multicolumn{2}{|c|}{ Due to dead load } & \multicolumn{2}{|c|}{ Due to superimposed dead } \\
\hline & & Mean $M_{\mathrm{DL}}(\mathrm{kNm})$ & Mean $V_{\mathrm{DL}}(\mathrm{kN})$ & Mean $M_{\mathrm{SDL}}(\mathrm{kNm})$ & Mean $V_{\mathrm{SDL}}(\mathrm{kN})$ \\
\hline \multirow{3}{*}{1 and 5} & Mid span & $1,185.30$ & - & 612.20 & - \\
\hline & End of cover plate & 314.47 & - & 162.42 & - \\
\hline & Support & 一 & 169.33 & 一 & 87.46 \\
\hline \multirow{3}{*}{2,3 , and 4} & Mid span & $1,185.30$ & - & 214.67 & - \\
\hline & End of cover plate & 314.47 & - & 56.95 & - \\
\hline & Support & - & 169.33 & - & 30.67 \\
\hline
\end{tabular}

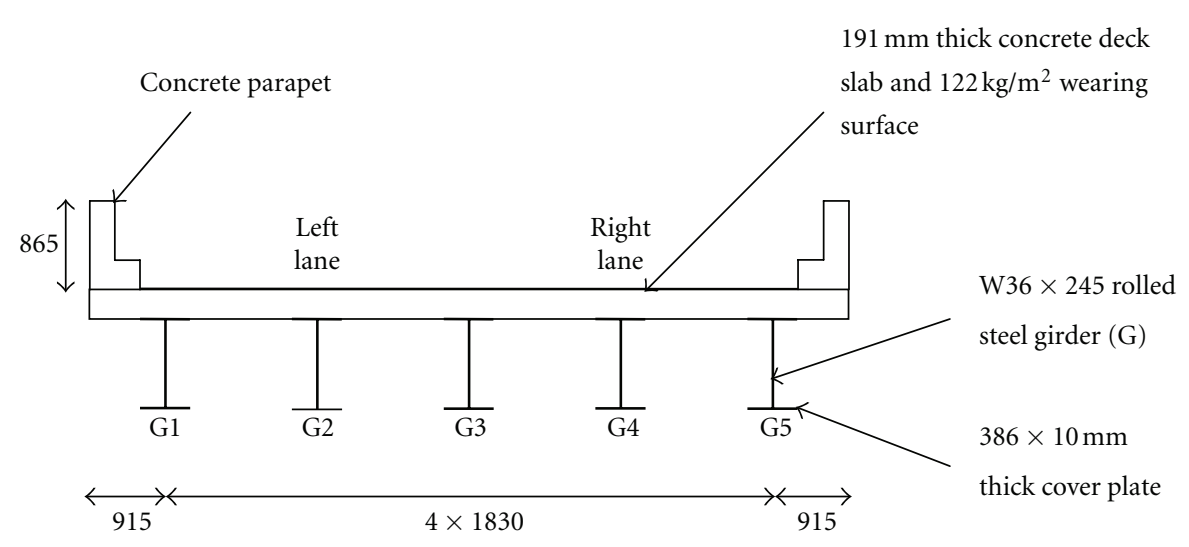

FIgURE 4: Typical cross section of two-lane rolled steel girder bridge (unit: $\mathrm{mm}$ ).

structure. The condition of the structure or its components is improved. However, similar damage may reoccur during the remaining life of the structure such that subsequent repair work is expected. The condition of the structure will be reset to the initial condition after major repair work.

(4) Rehabilitation repair (Rep, 4): it restores the durability, structural strength, and function or appearance of the structure and improves the durability performance of the repaired structure or its components. Similar damage may occur later with lower probability. The condition of the structure will be reset to the initial condition after the work.

(5) Replacement (Rep, 5): it refers to the replacement of existing members, which may improve local capacity, durability of the structure, and so forth. The condition of the structure will be reset to the initial condition after the work.

\section{Example of LCM Strategy of Steel Girders in Bridges}

A simply supported composite steel girder bridge with rolled-beam stringers is adopted as an example to illustrate the proposed LCM strategy. The bridge has a simple span of $28.0 \mathrm{~m}$ with two-lane traffic in the same direction. $191 \mathrm{~mm}$ thick concrete deck slab with wearing surface at weight $122 \mathrm{~kg} / \mathrm{m}^{2}$ is supported by five rolled steel girders at size W36 $\times 245$. Each girder has a welded cover-plate with size $386 \times$
$10 \mathrm{~mm}$ thick under bottom flange. $865 \mathrm{~mm}$ high of concrete parapets are installed at both sides. The distance from each end of the cover plate to the adjacent bearing is $2.0 \mathrm{~m}$. The cross section of the bridge is shown in Figure 4.

\subsection{Loading Analysis}

11.1.1. Dead and Superimposed Dead. It is assumed the dead and superimposed dead loads are normally distributed with coefficient of variation (C.O.V.) $0.1[9,10,21]$. The induced mean moments at the mid span and the end of cover plate and the induced mean shears at end supports are calculated and summarized in Table 3.

From Table 3, the maximum bending moment at mid span is $1,798 \mathrm{kNm}$, the bending moment at the ends of cover plates is $476.89 \mathrm{kNm}$, and the maximum shear load at supports is $257 \mathrm{kN}$ for Girder Nos. 1 and 5 . Whereas, for Girder Nos. 2, 3, and 4, the maximum bending at mid span is $1,400 \mathrm{kNm}$, the bending moment at ends of cover plates is $372 \mathrm{kNm}$, and the maximum shear load at supports is $200 \mathrm{kN}$.

11.1.2. Live and Impact. The live load on the bridge is assumed due to traffic only. Girders moments and shears summarized in Table 4 are calculated based on the survey results of Nowak [21] with literature references in which the average daily truck traffic (ADTT) is 5,000 with $66 \%$ of the cases that a truck was in the left lane, $33 \%$ of the cases that a truck was in the right lane, and $1 \%$ of the cases that trucks 


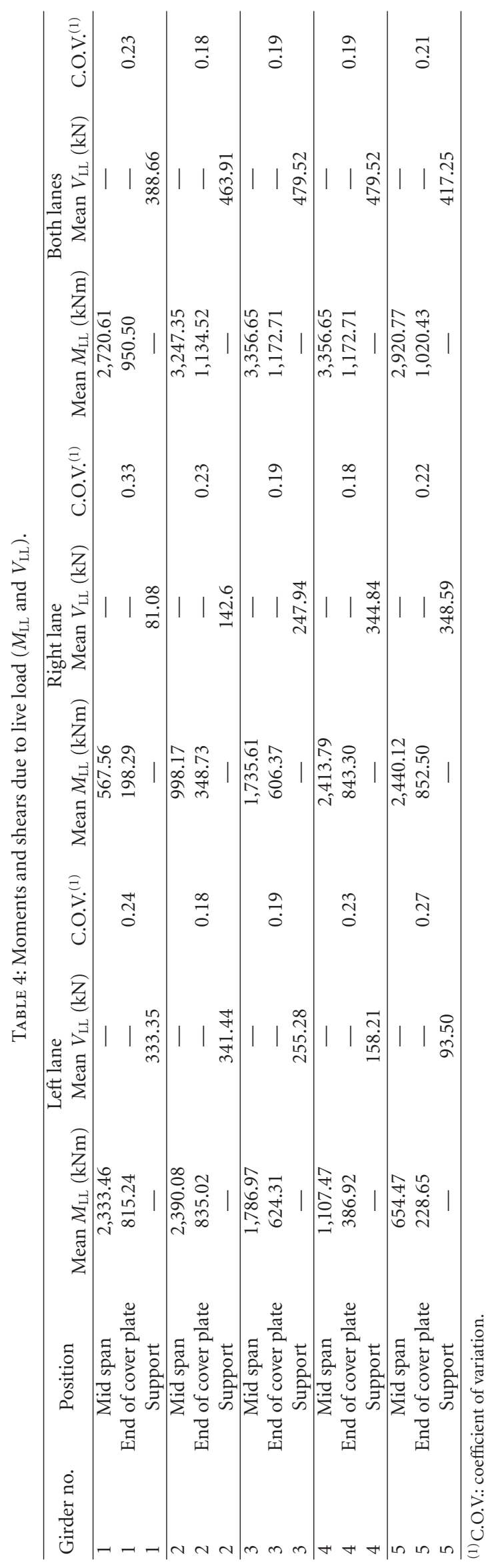


TABLE 5: Statistical parameters of random variables for the illustrative example.

\begin{tabular}{|c|c|c|c|c|c|c|}
\hline Parameters & Materials & Variables & Mean $(\mu)$ & C.O.V. ${ }^{(1)}(\sigma / \mu)$ & Distribution & Sources \\
\hline \multirow{6}{*}{ Corrosion deterioration rate } & \multirow{3}{*}{ Carbon steel } & $A$ & $70.6 \mu \mathrm{m}$ & 0.66 & \multirow{2}{*}{$\mathrm{LN}^{(2)}$} & \multirow{6}{*}[5,6]{} \\
\hline & & $B$ & 0.789 & 0.49 & & \\
\hline & & $\rho_{A B}$ & -0.31 & - & - & \\
\hline & \multirow{3}{*}{ Weathering steel } & $A$ & $40.2 \mu \mathrm{m}$ & 0.22 & \multirow{2}{*}{$\mathrm{LN}$} & \\
\hline & & $B$ & 0.557 & 0.10 & & \\
\hline & & $\rho_{A B}$ & -0.45 & - & - & \\
\hline Corrosion Initiation & - & $T_{\mathrm{CI}}$ & $15 \mathrm{yr}$ & 0.30 & \multirow{2}{*}{$\mathrm{LN}$} & \multirow{2}{*}[7]{} \\
\hline Repaint duration & - & $T_{\mathrm{REP}}$ & $20 \mathrm{yr}$ & 0.25 & & \\
\hline Initial crack dimension & \multirow{5}{*}{ Structural steel } & $a_{0}$ & $0.762 \mathrm{~mm}$ & 0.5 & \multirow{2}{*}{$\mathrm{LN}$} & \multirow{2}{*}[14]{} \\
\hline Crack growth constant & & $C$ & $1.26 \times 10^{-13}$ & 0.63 & & \\
\hline Crack growth exponent & & $m$ & 3 & - & \multirow{2}{*}{ Constant } & \multirow{2}{*}[15]{} \\
\hline Critical crack dimension & & $a_{c}$ & $0.0254 \mathrm{~m}$ & & & \\
\hline Fracture toughness & & $K_{\text {IC }}$ & $43.97 \mathrm{MPa} \mathrm{m}{ }^{0.5}$ & 0.19 & $\mathrm{TN}^{(3)}$ & {$[10]$} \\
\hline Compressive strength & Concrete & $f_{c}$ & $21 \mathrm{MPa}^{(4)}$ & 0.19 & \multirow{2}{*}{$\mathrm{LN}$} & \multirow{2}{*}[9]{} \\
\hline Yield stress & Steel & $F_{y}$ & $248 \mathrm{MPa}$ & 0.10 & & \\
\hline \multirow{2}{*}{ Modulus of elasticity } & Concrete & $E_{c}$ & $30,000 \mathrm{MPa}$ & 0.20 & \multirow{2}{*}{$\mathrm{LN}$} & \multirow{2}{*}[16]{} \\
\hline & Steel & $E_{s}$ & $210,000 \mathrm{MPa}$ & 0.06 & & \\
\hline Deck slab thickness & Concrete & $t_{c}$ & $191 \mathrm{~mm}$ & 0.20 & $\mathrm{~N}^{(4)}$ & {$[14]$} \\
\hline
\end{tabular}

TABLE 6: Deflection of steel girder bridge with cover plate.

\begin{tabular}{|c|c|c|c|c|c|c|}
\hline \multirow[b]{2}{*}{ Years } & \multicolumn{3}{|c|}{ Nominal corrosion penetration (mm) } & \multicolumn{3}{|c|}{ Nominal maximum deflection (mm) } \\
\hline & $\begin{array}{l}\text { Carbon steel } \\
\text { without coat }\end{array}$ & $\begin{array}{c}\text { Carbon steel } \\
\text { with coat }\end{array}$ & $\begin{array}{c}\text { Weathering } \\
\text { Steel }\end{array}$ & $\begin{array}{l}\text { Carbon steel } \\
\text { without coat }\end{array}$ & $\begin{array}{c}\text { Carbon steel } \\
\text { with coat }\end{array}$ & $\begin{array}{c}\text { Weathering } \\
\text { steel }\end{array}$ \\
\hline 0 & 0.000 & 0.000 & 0.000 & 29.332 & 29.332 & 29.332 \\
\hline 10 & 0.434 & 0.000 & 0.145 & 29.554 & 29.332 & 29.405 \\
\hline 20 & 0.750 & 0.251 & 0.213 & 29.719 & 29.460 & 29.440 \\
\hline 30 & 1.033 & 0.251 & 0.267 & 29.870 & 29.460 & 29.468 \\
\hline 40 & 1.297 & 0.503 & 0.314 & 30.012 & 29.589 & 29.492 \\
\hline 50 & 1.546 & 0.503 & 0.355 & 30.149 & 29.589 & 29.513 \\
\hline 60 & 1.786 & 0.754 & 0.393 & 30.282 & 29.721 & 29.533 \\
\hline 70 & 2.016 & 0.754 & 0.428 & 30.413 & 29.721 & 29.551 \\
\hline 75 & 2.129 & 0.754 & 0.462 & 30.478 & 29.721 & 29.560 \\
\hline
\end{tabular}

were in both lanes $[9,10,14]$. It is also assumed that the live load from vehicles is kept unchanged throughout the bridge's service life. To account for the dynamic effects of a vehicle riding over the bridge, an impact factor is adopted as a multiplier. The impact fraction of live load according to ASSHTO Specification (2004) [22] is 0.231. The moment and the shear due to impact will then be added on the live load schedule.

\subsection{Service Life Prediction}

11.2.1. Serviceability Limit: Deflection. Corrosion reduces the effective cross-section and occurs mainly at the web and the top of bottom flange of steel girders. Reduction of section area leads to weaken the flexural strength and the shear strength and increases the deflection of bridge deck under service loadings. According to the ASSHTO specification, the deflection limit due to live load plus impact is span $/ 800=35 \mathrm{~mm}$ for typical highway bridges. In order to investigate the long-term effectiveness of different preventive measures of steel girders, three scenarios include carbon steel without protective paint, carbon steel with protective paint, and weathering steel are compared. The steel bridge is modeled against corrosion in marine environment based on the statistical parameters listed in Table 5. The nominal maximum deflections under three different scenarios are calculated according to (1) to (3) and summarized in Table 6. 


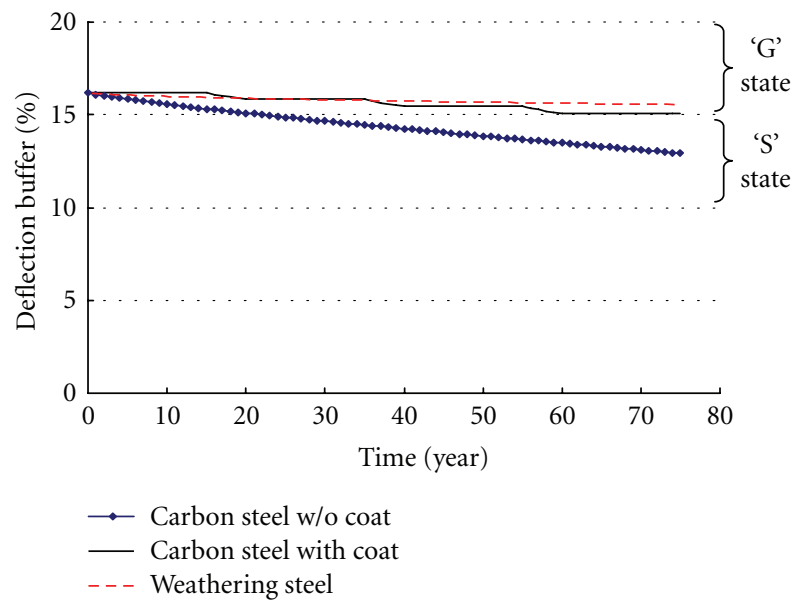

Figure 5: Deflection Buffer Over Life Span.

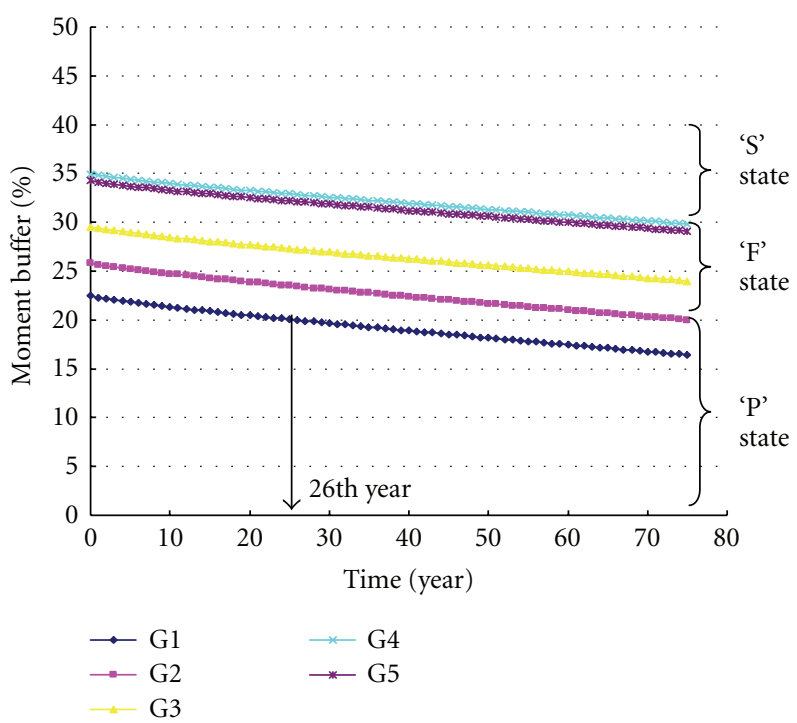

Figure 6: Moment buffer over life span of carbon steel girders.

The deflection buffer against time over the life span is plotted in Figure 5. Results show that the deflection for girders without any protective systems is the highest one while the deflection for girders made of weathering steel is the lowest. According to the proposed management strategy, throughout the 75 years service life, none of steel girder types falls below the fair condition state (i.e., " $F$ " - State) in the Deflection Condition State Set (i.e., (13)). In other words, no R\&R works for deflection is expected throughout the life span.

11.2.2. Ultimate Limits-Moment and Shear. It is assumed that R\&R actions only be taken places when condition reaches "P" state range in accordance with (14) and (15). Simulated time to reach " $P$ " state in terms of moment and shear buffer limits at 80 percentile value are plotted in Figures 6 and 7 respectively. Concerning the moment condition, result shows that Girder No. 1 will reach the moment buffer limit in the 26th year and the other girders will remain " $F$ " state and " $S$ " state throughout the life span. As to the shear condition, results demonstrate all girders will remain " $G$ " state that means shear stress causes insignificant impact to girders.

11.2.3. Fatigue Damage Limit. The maximum live load model developed above is insufficient to determine the effective range of the stress intensity factors. For fatigue analysis, the loading effects are modeled by the fatigue truck provided in the American Association of State Highway and Transportation Officials (AASHTO) specification with gross weight $240 \mathrm{kN}$. Each truck passage is assumed to cause one stress cycle only. Under repeated tensile stresses, fatigue cracks may form at the end weld of the cover plate and penetrate into the bottom flange. Under given bending moment in a girder, the critical fatigue stress is located in the bottom flange at the end of cover plate such that it should 


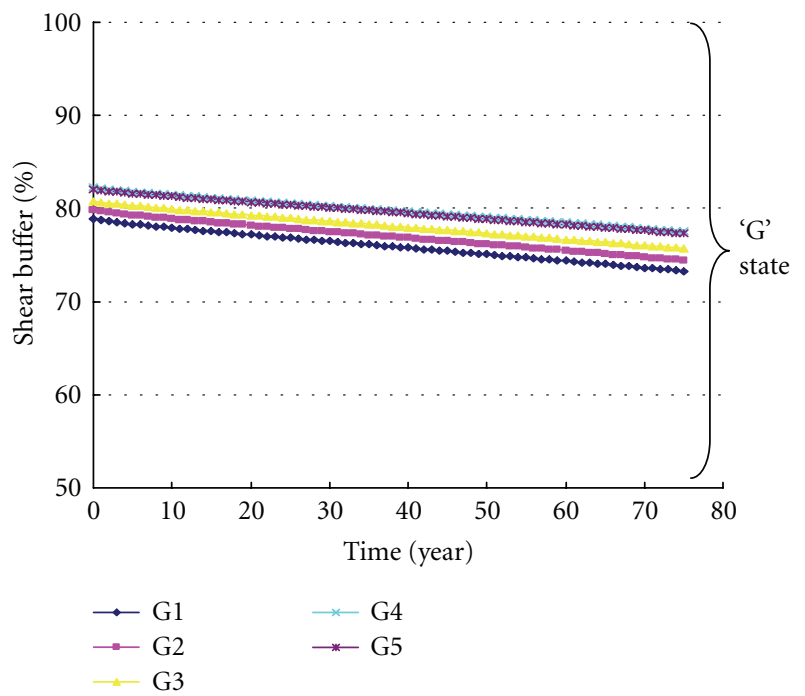

FIGURE 7: Shear buffer over life span of carbon steel girders.

TABle 7: Time (year) to " $P$ ” state of fatigue buffers.

\begin{tabular}{lc}
\hline Girder no. & Time \\
\hline G1 & 48 \\
G2 & 43 \\
G3 & 47 \\
G4 & 50 \\
G5 & 62 \\
\hline
\end{tabular}

be calculated based on the cross section of the girder without cover plate. The service life of each girder is simulated based on the statistical parameters in Table 5 and the simulated time for each girder to reach its " $P$ " state is summarized in Table 7.

Results show that girder no. 2 is the most sensitive girder to the fatigue damage, and it will reach the fatigue limit in the 43rd year.

\section{Discussion}

There are two important messages incurred from the example: (1) fatigue damages may not always dominate. Conventional LCM is in accordance with fixed predefined limit states either the serviceability limit or the ultimate limits or the fatigue limit. However, it may not be always valid that one limit dominates over one another or vice versa under all situations. Results demonstrate that the earliest simulated replacement or rehabilitation time for girders under bending stress is in the 26th year while the earliest simulated repair time for girders under fatigue damages is in the 43th year and (2) service lives of each girders are various. Conventional management approach treats all girders on equal ground. However, some girders may deteriorate faster than expected and some may not. In the case of fatigue damages, girder no. 5 has the longest life while girder no. 2 has the shortest one. Concerning the bending failure, the most critical one is girder no. 1 while the least are girder nos. 4 and 5 .

Service life prediction models integrated into the management strategy could provide a better picture for the stakeholders to identify the sensitive steel girder under corrosion deterioration or fatigue damages. Other factors affecting the condition of steel girders are neglected in the paper. However, steel components damages are definitely not conclusive to these two types.

Moreover, proposed acceptable limits can be further tied into reliability index if sufficient statistical information of the parameters in deterioration models is available. The rehabilitation time can be determined by the predefined reliability index value. Even though the reliability assessment has not been incorporated in this paper, the proposed LCM concept is not affected.

Furthermore, owing to the lack of sufficient cost data, the paper only addresses the LCM strategy and the methodology of service life prediction models being integrated into the LCC model. If sufficient financial data is available, it could provide further decision making information for selecting the most appropriate management strategy by LCC comparison.

\section{Further Research Approach}

Further research approach on the proposed flow for LCM strategy on steel girder in bridges as shown in Figure 8 can be conducted to test and verify its practicability. The proposed verification approach is categorized into 7 stages from Design Stage to Analysis Stage. However, some key important data should be obtained in the investigation stage prior to the LCC analysis process.

(1) Cost Data. Collection of possible future cost data is necessary to provide further decision making information for selecting the most appropriate management strategy. 


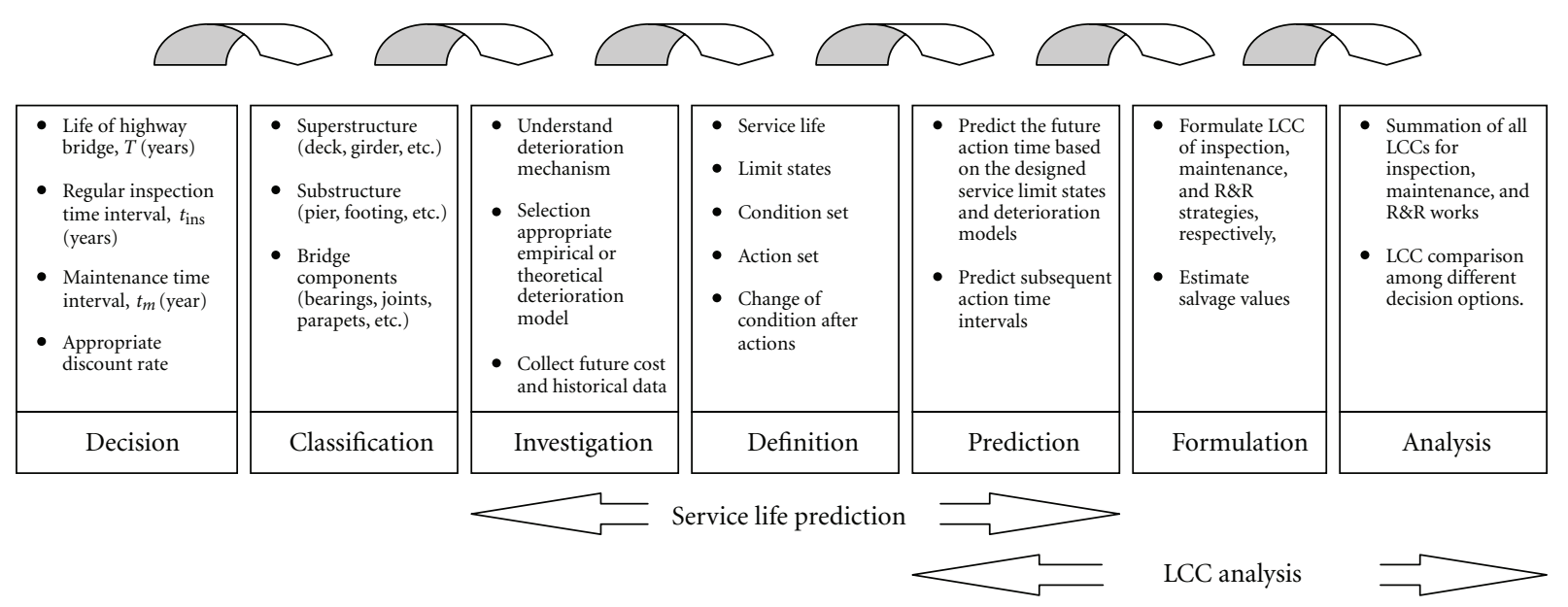

FIGURE 8: Suggested LCM flows for inspection, maintenance, and replacement and rehabilitation Works.

The cost of different types of future work should comprise inspection, operation, maintenance, management, repair, rehabilitation, replacement, demolition and failure.

(2) Historical Data. Collection of historical repair or rehabilitation data can be used to estimate the probability of any occurrence in case the future action time could not be predicted by appropriate deterioration models.

(3) Deterioration Mechanism. Steel component damage is definitely not exclusive to corrosion deterioration and fatigue damage. In the study, other factors affecting the condition of the steel girders are neglected. In fact, the bearing capacity of the steel girders and deterioration of other bridge components such as bridge bearings, expansion joints, and profile barriers could be incorporated into the LCM strategy. The proposed LCM strategy can be further enlarged.

\section{Conclusion}

Technical review on structural steel corrosion and fatigue models is addressed in this paper. However, in order to properly develop a LCM strategy for steel bridges in particular regions, it is necessary to consider some adjustments of parameters on the service life prediction models to suit the regional characteristics and needs. Further investigations on different empirical models under Hong Kong environments will be undertaken to identify the most appropriate empirical models for service life prediction purpose.

This paper proposes an integrated LCM framework assisting stakeholders to appropriately and reasonably prioritize their future maintenance-related works on steel girders in their bridge stocks such that stakeholders can better allocate the limited resources. In the framework, corrosion deterioration and fatigue damage prediction models are mapped with girders' performance conditions on deflection, ultimate moment and shear capacities, and fatigue strength limit simultaneously. The illustrative example on the proposed strategy on steel girders is also provided to demonstrate its applicability.

\section{Acknowledgment}

The work was financially supported by the Research Grants Council of the Hong Kong Special Administrative Region, China under Grant no. 610505.

\section{References}

[1] T. Obata, A. Nakajima, and K. Maeda, "Study on application of reliability analysis for bridge management system on steel bridge structures," in Life-Cycle Cost and Performance of Civil Infrastructure Systems, H.-N. Cho, D. M. Frangopol, and A. H.S. Ang, Eds., p. 291, Taylors \& Francis Group, London, UK, 2007.

[2] Queensland, "Another \$2 billion for Queensland infrastructure," Engineers Australia, vol. 77, no. 11, 25 pages, 2005.

[3] A. A. Czarnecki and A. S. Nowak, "Time-variant reliability profiles for steel girder bridges," Structural Safety, vol. 30, no. 1, pp. 49-64, 2008.

[4] M. Tavakkolizadeh and H. Saadatmanesh, "Fatigue strength of steel girders strengthened with carbon fiber reinforced polymer patch," Journal of Structural Engineering, vol. 129, no. 2, pp. 186-196, 2003.

[5] P. Albrecht and A. H. Naeemi, "Performance of weathering steel in bridges," National Cooperative Highway Research Program Report, 1984.

[6] J. R. Kayser, The effects of corrosion on the reliability of steel girder bridges [Ph.D. thesis], University of Michigan, Ann Arbor, Mich, USA, 1988.

[7] K. M. Lee, H. N. Cho, and C. J. Cha, "Life-cycle cost-effective optimum design of steel bridges considering environmental stressors," Engineering Structures, vol. 28, no. 9, pp. 1252-1265, 2006.

[8] M. S. Cheung and W. C. Li, "Serviceability reliability of corroded steel bridges," Canadian Journal of Civil Engineering, vol. 28, no. 3, pp. 419-424, 2001.

[9] A. M. Sommer, A. S. Nowak, and P. Thoft-Christensen, "Probability-based bridge inspection strategy," Journal of Structural Engineering, vol. 119, no. 12, pp. 3520-3536, 1993. 
[10] M. Jiang, R. B. Corotis, and J. Hugh Ellis, "Optimal life-cycle costing with partial observability," Journal of Infrastructure Systems, vol. 6, no. 2, pp. 56-66, 2000.

[11] Z. Zhao, A. Haldar, and F. L. Breen Jr., "Fatigue-reliability evaluation of steel bridges," Journal of Structural Engineering, vol. 120 , no. 5, pp. 1608-1623, 1994.

[12] C. MacDougall, M. F. Green, and S. Shillinglaw, "Fatigue damage of steel bridges due to dynamic vehicle loads," Journal of Bridge Engineering, vol. 11, no. 3, pp. 320-328, 2006.

[13] J. Mohammadi, S. A. Guralnick, and R. Polepeddi, "Bridge fatigue life estimation from field data," Practice Periodical on Structural Design and Construction, vol. 3, no. 3, pp. 128-133, 1998.

[14] M. S. Cheung and W. C. Li, "Probabilistic fatigue and fracture analyses of steel bridges," Structural Safety, vol. 25, no. 3, pp. 245-262, 2003.

[15] J. W. FISHER, Fatigue and Fracture in Steel Bridges, Case Studies, John Willey \& Sons, New York, NY, USA, 1984.

[16] M. S. Cheung and W. C. Li, "Serviceability reliability of corroded steel bridges," Canadian Journal of Civil Engineering, vol. 28, no. 3, pp. 419-424, 2001.

[17] K. K. L. So, M. M. S. Cheung, and E. X. Q. Zhang, "Lifecycle cost management of concrete bridges," Proceedings of the Institution of Civil Engineers: Bridge Engineering, vol. 162, no. 3, pp. 103-117, 2009.

[18] A. Saloranta, "High performance coatings for steel bridges," Progress in Organic Coatings, vol. 22, no. 1-4, pp. 345-355, 1993.

[19] C. K. Tam and S. F. Stiemer, "Development of bridge corrosion cost model for coating maintenance," Journal of Performance of Constructed Facilities, vol. 10, no. 2, pp. 47-56, 1996.

[20] W. Radomski, Bridge Rehabilitation, Impress College Press, 2002.

[21] A. S. NOWAK, "Calibration of LRFD bridge design code," Final Report prepared for NCHRP, TRB, National Research Council, Deparment of Civil Engineering, University of Michigan, Ann Arbor, Mich, USA, 1993.

[22] ASSHTO LRFD Bridge Design Specifications, American Association of State Highway and Transportation Officials, Washington, DC, USA, 2004. 

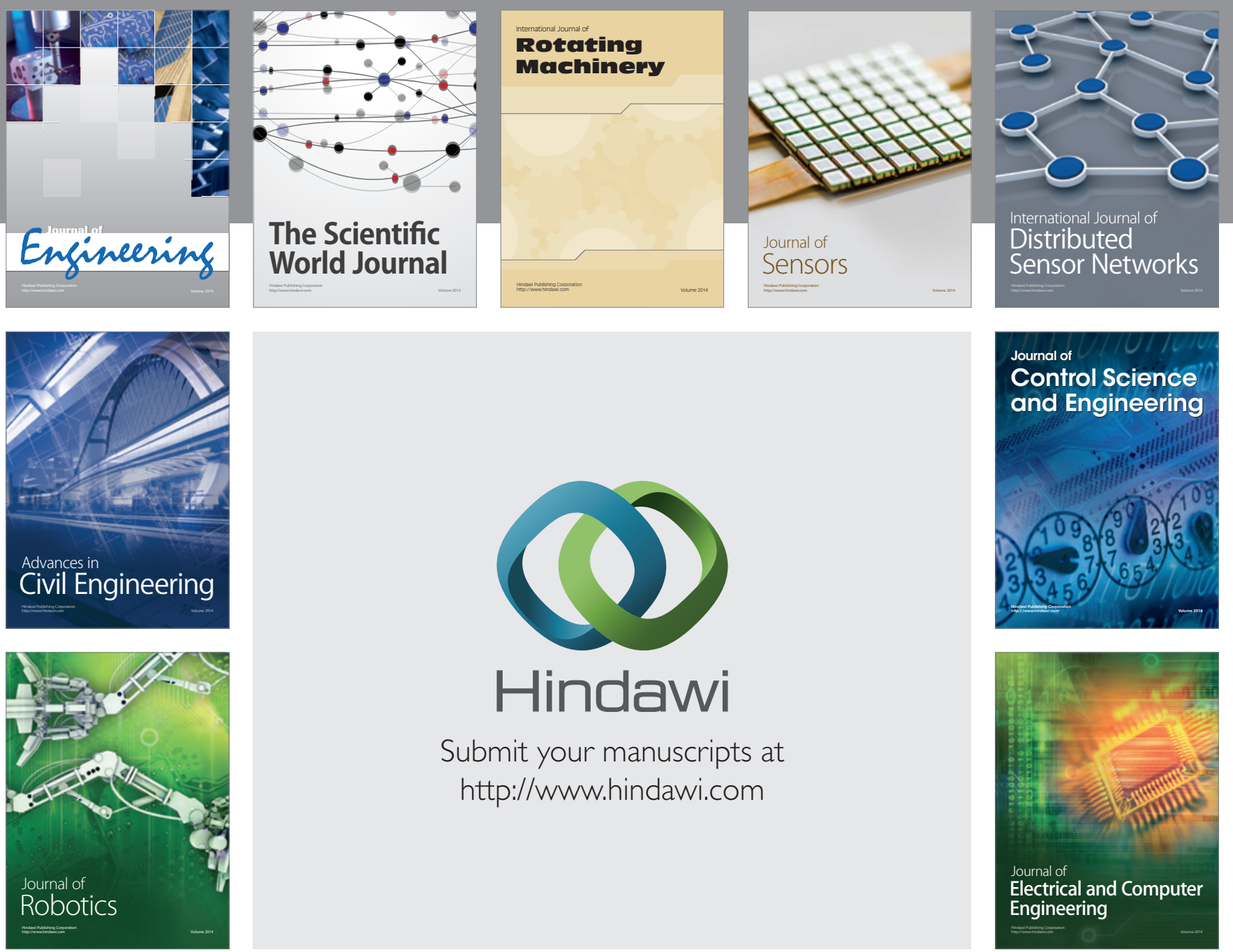

Submit your manuscripts at

http://www.hindawi.com
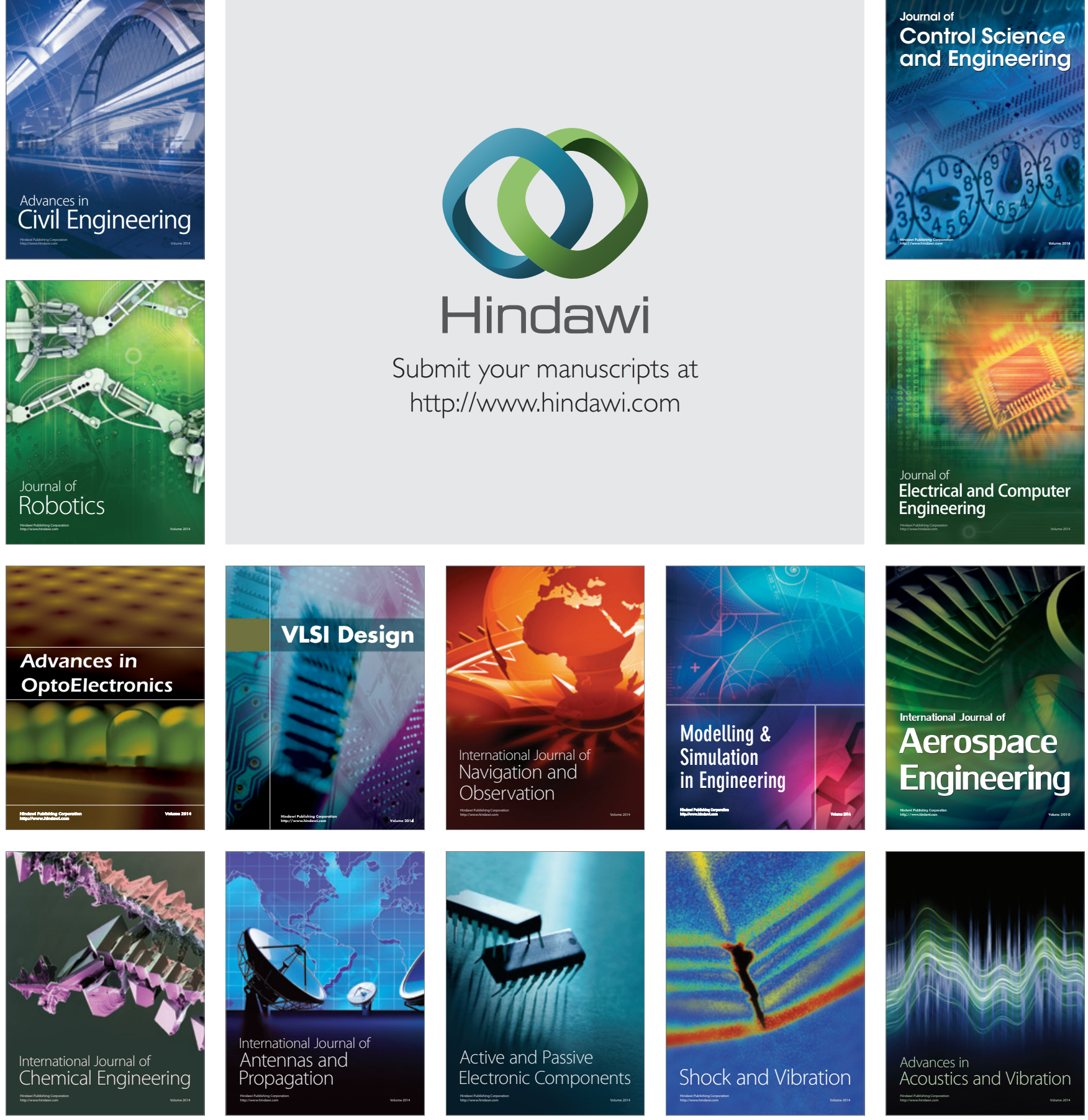